\title{
Objective Structured Clinical Examination in Undergraduate Pharmacy Students: Time to Switching to an Alternative Exam for Clerkship Courses
}

\author{
Sarah Mousavi ${ }^{*}$, Mohammdreza Amirsadri ${ }^{1}$ \\ 1'Department of Clinical Pharmacy and Pharmacy Practice, Faculty of Pharmacy and Pharmaceutical Sciences, Isfahan University of \\ Medical Sciences, Isfahan, Iran.
}

\begin{abstract}
Background: Significant changes in the clinical context of health professional education and impressive body of research on the measurement of clinical competence support the use of the Objective Structured Clinical Exam (OSCE) as the preferred means of performance-based assessment to current teaching and evaluation method. The objective of this paper is to describe how the OSCE method was developed and applied to an undergraduate community pharmacy clerkship course, as a pilot for assessing clinical competence and skills of these students. Methods: A seven-station OSCE was designed and implemented to assess the learning objectives of community pharmacy clerkship course(s) in the Pharmacy Doctorate program of pharmacy curriculum of the Isfahan University of Medical Sciences. The key process in designing and implementing the OSCE includes: development and face-validation of seven stations in accordance with our learning objectives of the course; designing of dichotomous performance checklists or suitable assessment instruments for individual stations; and conducting of the final examination. The broad competencies tested in the OSCE included: drug labeling, patient education and counseling, drug usage instruction, reading and evaluating prescriptions and use of drug information resources (electronic or hard copy texts) for determining probable drug interactions. Results: The students scored the highest marks in use of drug information resources for determining probable drug interactions (mean \pm SD: $5.6 \pm$ 0.68 ) and the lowest marks in drug usage instruction (mean \pm SD: $4.8 \pm 0.56$ ). Most of the students $(84 \%)$ found OSCE as an appealing and useful method of assessment. Conclusion: The assessment methods and educational objectives should be aligned with each other. Although OSCE is not commonly used in Iranian pharmacy schools, however, due to the practical nature of clerkship courses of the pharmacy doctorate program, OSCE seems to be a more suitable and relevant method to evaluate the community pharmacy clerkship course compared to conventional written exams.
\end{abstract}

Key words: Educational Assessment, Pharmacy Students, Pharmacy Education, Clinical Clerkships, Educational Measurements.
Submission Date : 15-06-2016 Revision Date : 28-09-2016 Accepted Date : :28-09-2016

DOI: 10.5530/ijper.50.4.2 Correspondence: Dr Sarah Mousavi, Department of Clinical Pharmacy and Pharmacy Practice, Faculty of Pharmacy and Pharmaceutical Sciences, Isfahan University of Medical Sciences, HezarJerib Avenue, Isfahan, IRAN. Tel/Fax:+ 983137927072. E-mail: s.mousavi@pharm. mui.ac.ir

\section{INTRODUCTION}

Nowadays, pharmacy practice has shifted from the traditional role as dispensing and distributing drugs to a patient-centered practice. This implicates the cooperation of pharmacists with other health care providers for health promotion, disease prevention, assessing, monitoring, and modification of medication use to assure that drug therapy regimens are safe and effective. ${ }^{1}$ to reach the goal of pharmaceutical care, pharmacists need to be aware of not merely drug dispensing but also clinical drug-related

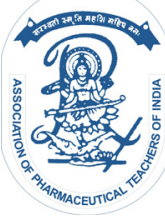

www.ijper.org 
issues and patient communication skills. As a result, the pharmaceutical education program and its curricula and assessment methods need restructuring. ${ }^{2}$ The Pharm D. education program of the Iranian universities was revised in 2005, within which pharmaceutical care courses increased both quantitatively and qualitatively. $^{3}$

In view of the fact that about $90 \%$ of Iranian pharmacy students begin to work in pharmacies after their graduation, the pharmacy clerkship (basic community pharmacy clerkship) courses and the internship are of particular importance within the Pharm D. educational program. In Iran's pharmacy curriculum, pharmacy clerkship courses are defined as the "courses offered are aimed at educating practical skills in the field of health care services". "These courses constitute 6 credits of the Pharm D. curricula. The main goal of pharmacy clerkship course is to get students familiar with most used drug categories, reading and assessing prescriptions, drug labeling and patient education, skills to answer the patients' or health care providers' questions and practical use of drug information resources. ${ }^{5}$

The traditional assessment methods of pharmacy clerkship courses include a written exam or oral exam or a combination of both. As explained, these assessment methods do not seem capable to assess the practical clinical competence of the pharmacy students. The Objective Structured Clinical Examination (OSCE), is of the performance-based assessment methods which have been recognized as the gold standard tool for evaluating the clinical competency of medical and pharmaceutical undergraduate students. ${ }^{6,7}$ OSCE has been rated as the most reliable and valid tool of assessing clinical competency as well., ${ }^{8,9}$ An OSCE is comprised of a series of stations through which all candidates rotate on a timed basis. In each station, candidate faces with a simulated task or problem; these candidates are asked to perform a specific task or deal with the addressed problem. $^{10,11}$ As a performance based assessment method, OSCE measures cognitive learning, essential practice skills, and ability to communicate effectively using problem solving skills.

Due to the importance of pharmacy clerkship courses in the education of pharmacy students, a standard method for evaluating pharmacy student's skills is required. This report represents our first experience in the develop and conduct an OSCE exam for the pharmacy clerkship course at pharmacy and pharmaceutical school affiliated to Isfahan University of Medical Sciences (IUMS).

\section{METHODS}

A seven-station OSCE was developed to assess the pharmacy student's knowledge, clinical and practical skills. All of the pharmacy students of pharmacy faculty affiliated to IUMS who had chosen community pharmacy clerkship 2 courses in the second semester of the academic year 2015-2016, participated in this study.

The course of community pharmacy clerkship 2 is offered in each second semester to fourth-year pharmacy doctorate students who have fulfilled the required prerequisites including community pharmacy clerkship1 course. This course is a three credit-hour faculty required (core) course with a total of 110 content hours, including 54 contact hours $(28 \times 2$ hour) for didactic lectures (on drug information) and 56 contact hours ( $14 \times 4$ hour) for a clerkship in teaching-based pharmacies. The amount of workload in this course stands at about two times of the total workload (credit hours required) in the fourth year syllabus.

The key learning outcomes of the course include: reading and evaluating prescriptions, patient education (on drug information, adverse effects of drug, drug usage instruction and drug-drug interactions), and skills to answer the questions of patients and medical staffs and ability to use of drug information resources. The students were assessed for this course using written exam (70\%) and an OSCE (30\%).

\section{Process for OSCE development}

First of all, the course coordinator (assistant professor of clinical pharmacy) developed a blueprint consisting of the structure and development of proposed work stations, assignment of responsibilities, examination venue, required supplies and financial resources. In the second phase, several meetings were organized by faculty members of a clinical pharmacy department to discuss station development, plan and design the assessment cases in consonance with the blueprint. In designing the workstations and assessment methods the educational and practical aims of the course, including the clinical skills and competences as well as the learning outcomes and appropriateness of the scoring strategy were taken into account. In the third phase, OSCE station component was developed, including the assessment instruments and the required instruction for both candidates and examiners. The marking schemes were prepared in the form of dichotomous checklists for all the planned stations. The checklist items were individualized for each of the stations. The checklist items were face-validated later by both the department head (assistant professor of pharmaco economics) and the course coordinator. (Samples of these materials can be available upon request). At the end stage, the course coordinator 
organized, two days prior the examination day to make sure that all examiners are aware of the examination method, the structure of the designed stations and proceeding of the session.

The seven-station OSCE contributed 6 marks out of 20 of the course $(0.5$ marks for each of the first 3 stations, 1.5 marks for each of the stations 4 and 7 and 0.75 marks for the stations 5 and 6 ).

\section{Overview of the OSCE}

A: The OSCE took place in IUMS' center for clinical skills education (CCSE) which is used for case development, consultation, assessment and teaching of clinical skills. The CCSE consists of examination rooms, a recording room and an observation room where the encounters can be viewed in real time. B: All the faculty members $(\mathrm{N}=7)$ of the Clinical Pharmacy department, who had already enrolled in the teaching of the course, collaborated in the OSCE as examiners. C: At each of the designed stations (either preparatory or assessing), the students were requested to perform a specific task according to the given instruction. An assessor presented in each station and assessed the students using a structured marking guide. The time keeper buzzed at the end of each 4-minute session and the students rotated to next session accordingly. D: The OSCE was performed in two consecutive sessions for two groups of students (31 for each). The second group quarantined until the ending of the first session. Each of the sessions comprised of seven stations as follows; in first three stations $(1,2,3)$, students encountered a chosen real prescription of drugs in each station and were asked to evaluate it in terms of number, type and dosage form of the prescribed medications and to correct the probable medical errors. In stations $(4 \& 7)$, the students were asked to examine the usage instruction of some prepared dosage forms, to prepare a label for the medication and give required advice on use of the drugs to the pretend patient. In station number five, students should explain usage instruction of different dosage forms (including inhalers, insulin pens, vaginal tablets or cream and nasal, ear or eye drops, prefilled syringes...). The station number six was equipped with computer and drug information resources to assess student's skill in finding and managing drug interactions in real prescriptions. E: Different scenarios with identical levels of difficulty designed and changed for each 7 students to make sure that students are not aware of the questions. Furthermore, a questionnaire survey was conducted to obtain the students' feedback on the OSCE (as a new assessment tool) for the educated course. The questions were developed in five choices "Likert" scales, in which
5,4,3,2 and 1 stand for completely positive, positive attitude, somewhat agree, negative attitudes, and completely negative attitudes respectively.

The collected data were analyzed using SPSS version 20 . Descriptive statistics were calculated to determine frequencies, mean and standard deviation.

\section{RESULTS}

An OSCE was successfully developed and applied to test the clinical competencies of fourth-year pharmacy students. 62 students in total participated the OSCE. The overall performance in the OSCE was 5.1 out of 6 marks as the class average. The min and the max marks obtained were $3.5 / 6$ and 5.8/6 respectively.

Individual OSCE station scores with the related means $\pm \mathrm{SD}$, and maximum and minimum marks obtained by the students are illustrated in Table 1 . The students scored the highest marks in drug interaction checking and managing (mean $\pm \mathrm{SD}=5.6 \pm 0.68$ ) and the lowest marks in the explaining the usage instruction of different dosage forms (mean $\pm \mathrm{SD}=4.8 \pm 0.56$ ).

Table 2 shows the results of the questionnaire survey. Students generally found this method of assessment appealing and most of them agreed that the designed OSCE stations were compatible with the real community pharmacies context and the educated materials.

\section{DISCUSSION}

This study was the first experience of developing and applying an OSCE in the pharmacy faculty of Isfahan University of Medical Sciences. Before this, the written exam was the only assessment method to evaluate the students in the community pharmacy clerkship course in our faculty, which could not be capable to assess the student' skill. Developing a method of assessment which enable us to evaluate the pharmacy students practical skills is of particular importance, as the majority of these students will work in the near future in community pharmacies as a pharmacist in charge.

Although the evaluated students performed well in the fields of dispensing, labeling and patient education; however, they gained the minimum scores in the explaining dosage form instruction, so this might be due to the weakness of the education course plan in the mentioned area. Kouti et al., ${ }^{3}$ had the similar experience in designing and implementing OSCE exam for pharmacy clerkship course in pharmacy faculty in Ahvaz, Iran. They also compared the results of their OSCE with a conventional test. Their OSCE exam consisted of six different stations, including reading prescription, identifying drugs, patient 


\begin{tabular}{|c|c|c|c|c|c|}
\hline Task at the station & $\begin{array}{l}\text { Station } \\
\text { number }\end{array}$ & Mean \pm SD & Max score & Min score & No. students \\
\hline $\begin{array}{l}\text { Matching the prescription with the drugs given } \\
\qquad(\text { marks;1.5) }\end{array}$ & $1,2,3$ & $1.2 \pm 0.21$ & 1.5 & 0.8 & 62 \\
\hline Explaining dosage form usage instruction (marks:0.75) & 5 & $0.6 \pm 0.07$ & 0.75 & 0.4 & 62 \\
\hline $\begin{array}{l}\text { Finding drug interaction in prescription/ by using drug } \\
\text { information resources (marks:0.75) }\end{array}$ & 6 & $0.71 \pm 0.08$ & 0.75 & 0.5 & 62 \\
\hline $\begin{array}{l}\text { Writing usage instruction/ labeling of the drugs/patient } \\
\text { education (marks:3) }\end{array}$ & 4,7 & $2.5 \pm 0.37$ & 3 & 1.43 & 62 \\
\hline Total (marks:6) & & $5.1 \pm 0.46$ & 5.8 & 3.5 & 62 \\
\hline
\end{tabular}

\begin{tabular}{|c|c|c|c|c|c|}
\hline Questions & $\begin{array}{l}\text { Completely positive } \\
\text { (N/\%) }\end{array}$ & Positive (N/\%) & $\begin{array}{c}\text { Somewhat agree } \\
(\mathrm{N} / \%)\end{array}$ & Negative (N/\%) & $\begin{array}{c}\text { Completely negative } \\
\text { (N/\%) }\end{array}$ \\
\hline $\mathrm{Q}^{1}$ & $34(56.6 \%)$ & $17(28.3 \%)$ & $8(13.3 \%)$ & 0 & $1(1.6 \%)$ \\
\hline$Q^{2}$ & $16(26.6 \%)$ & $20(33.3 \%)$ & $20(33.3 \%)$ & $4(6.6 \%)$ & 0 \\
\hline $\mathrm{Q}^{3}$ & $20(33.3 \%)$ & $18(30 \%)$ & $14(23.3 \%)$ & $7(11.6 \%)$ & $1(1.6 \%)$ \\
\hline $\mathrm{Q}^{4}$ & $18(30 \%)$ & 20 (33.3\%) & $9(15 \%)$ & $8(13.3 \%)$ & $5(8.3 \%)$ \\
\hline
\end{tabular}

Q1: Instruction before exam was clear and beneficial.

Q2: Setting and content at each station were compatible with real situations at community pharmacies (felt authentic)

Q3: Allocated time at stations was adequate.

$\mathrm{Q}_{4}$ : OSCE exam was appealing for me.

education, drug information resources and drug usage instruction. The authors didn't find any significant correlation between OSCE final scores and written test scores. The least score was in the drug information resources station and controlling the prescriptions.

Although the minimum requirements for teaching the pharmacy clerkship course has been defined by the educational affaires of the ministry ofhealth and medical education of Iran, pharmacy schools have different strategies to offer the course, due to the differences in their available facilities. This might be explaining the difference between the results of the current study with the Kouti et al.,. ${ }^{3}$ To achieve similar results of the conducted intervention, it is recommended to improve the required facilities for the execution of the community pharmacy clerkship course in accordance with the educational affairs of the Iranian ministry of health and medical education.It would be possible to adopt a global method to assess the students for this course. According to our experience of this proceeding, we believe that the OSCE is the preferred method to assess the students for the practical aspects of the evaluated course. This method of evaluation, not only can be used to assess the students' skill, but also can clarify the weakness points of the course curriculum and help in revising it.

Awaisu et al., ${ }^{12}$ in 2010 designed and performed an OSCE exam for undergraduate pharmacy program in
Malaysia. The authors found OSCE a technically feasible method and a great success in pharmacy student's education program which could have a great positive impact on providing efficient pharmaceutical care services. The results of Awaisu et al., ${ }^{12}$ study showed that the students achieved the least scores in the drug information task and competency. Another study of the Awaisu et al., ${ }^{13}$ in 2007 showed that the pharmacy students, believe that OSCE could provide a useful and practical learning experience. Our students also found the OSCE appealing and practical.

\section{CONCLUSON}

To make the story short, the assessment methods need to be designed in accordance with the educational course requirements. Considering the practical nature and objectives of clerkship courses, the OSCE can be considered as an acceptable method of assessment; although designing and conducting of an OSCE is revising the evaluation process and could be considered as an effective step towards the training of efficient pharmacists for delivering pharmaceutical care services.

\section{ACKNOWLEDGEMENT}

The authors wish to thank the other member of the clinical pharmacy department at Isfahan University of 
Medical Sciences for their support and help throughout the performance of the exam.

\section{CONFLICT OF INTEREST}

None of the authors received any financial support or grant that may lead to the conflict of interest.

\section{ABBREVIATION USED}

OSCE: Objective Structured Clinical Examination; Pharm D.: Doctorate of Pharmacy.

\section{REFERENCES}

1. Cipolle RJ, Strand LM, Morley PC. Pharmaceutical care practice: the patient-centered approach to medication management. Third edition.New York:McGraw Hill Professional; 2012.

2. Schommer JC, Cable GL. Current status of pharmaceutical care practice: strategies for education. Am J Pharm Educ. 1996;60(1):36-41

3. Kouti L, Khezrian M, Eslami A, Assarian M, Zargar H, Mahdavinia M, et al. Designing Objective Structured Clinical Examination in Basic Community Pharmacy Clerkship Course and Assessment of Its Relationship with Conventional Exam. J Pharm Care. 2014;2(3):110-3.

4. Imo H. Regulation of pharmacy education (Pharm.D) course in Iran 1383. Available from: URL: http://http://hcmep.behdasht.gov.ir/uploads/Ayeen_ Daroo83.pdf.
5. Imo H. Pharmacy (Pharm.D) education program and curriculum. Available from:URL: http://http://epsc.behdasht.gov.ir/uploads/pharmd_ generalpharmacy.pdf.

6. Harden RM, Gleeson F. Assessment of clinical competence using an objective structured clinical examination (OSCE). Med Educ. 1979;13(1):39-54. http://dx.doi.org/10.1111/j.1365-2923.1979.tb00918.x

7. Hurley KF. OSCE and clinical skills handbook. Second Edition. Amsterdam:: Elsevier Saunders; 2005.

8. Kirton SB, Kravitz L. Objective structured clinical examinations (OSCEs) compared with traditional assessment methods. Am J Pharm Educ. 2011;75(6):111. http://dx.doi.org/10.5688/ajpe756111; PMid:21931449 PMCid:PMC3175669

9. Patrício MF, Julião M, Fareleira F, Carneiro AV. Is the OSCE a feasible tool to assess competencies in undergraduate medical education?. Med Teach. 2013; 35(6):503-14. http://dx.doi.org/10.3109/0142159X.2013.774330; PMid:23521582

10. Hastings JK, Flowers SK, Pace AC, Spadaro D. An objective standardized clinical examination (OSCE) in an advanced nonprescription medicines course. Am J Pharm Educ. 2010;74(6):98. http://dx.doi.org/10.5688/ aj740698; PMid:21045940 PMCid:PMC2933028

11. Adome RO, Kitutu F. Creating an OSCE/OSPE in a resource-limited setting. Med Educ. 2008;42(5):525-6. http://dx.doi.org/10.1111/j.13652923.2008.03045.x ; PMid:18412902

12. Awaisu A, Mohamed MHN. Advances in pharmaceutical education: an experience with the development and implementation of an objective structured clinical examination (OSCE) in an undergraduate pharmacy program. Pharm Educ. 2010;10(1):32-8.

13. Awaisu A, Mohamed MHN, Al-Efan QAM. Perception of pharmacy students in Malaysia on the use of objective structured clinical examinations to evaluate competence. Am J Pharm Educ. 2007;71(6):118. http://dx.doi.org/10.5688/ aj7106118; PMid:19503702 PMCid:PMC2690929

\section{SUMMARY}

- According to our experience of this proceeding, we believe that the OSCE is the preferred method to assess the students for the practical aspects of the evaluated course. This method of evaluation, not only can be used to assess the students' skill, but also can clarify the weakness points of the course curriculum and help in revising it. Considering the practical nature and objectives of clerkship courses, the OSCE can be considered as an acceptable method of assessment.

\section{About Authors}

S.M designed the OSCE exam, did the statistical analysis and drafted the manuscript . M.A revised and edited the manuscript. Both authors have read and approved the final version of the manuscript. 